\title{
A Novel Method of Orienting Hydraulic Fractures in Coal Mines and Its
}

\section{Mechanism of Intensified Conduction}

\author{
Yong $\mathrm{Liu}^{\mathrm{a}}{ }^{\mathrm{a} b}$, Binwei Xia ${ }^{\mathrm{a} *}$, Xiaotian $\mathrm{Liu}^{\mathrm{c}}$
}

a. State Key Laboratory of Coal Mine Disaster Dynamics and Control, Chongqing University, Chongqing, China;

b. State Key Laboratory Cultivation Base for Gas Geology and Gas Control, Henan Polytechnic University, Jiaozuo, China;

\footnotetext{
c. Safety Technology Training Institute, Henan Polytechnic University, Jiaozuo, China)
}

Abstract: With increasing coal mining depth, coal-bed methane (CBM) extraction becomes increasingly difficult, especially for underground CBM extraction. This paper proposes a method for the efficient extraction of $\mathrm{CBM}$ in underground coal mines that orients a borehole around a hydraulic fracturing borehole, uses a high-pressure water jet to perforate parallel to the coal bed inclination in the boreholes, and finally performs hydraulic fracturing. Because of shear failure at the perforation tip, cracks initiate at the perforation tip during hydraulic fracturing. Moreover, the perforation causes the maximum principal stress at an angle approximately parallel to the perforation axial, which leads to the orderly propagation of the crack in the coal. The initiation pressure of hydraulic fracturing with and without perforation is compared. Under the same stress combination, the initiation pressure is lower for boreholes with perforation than for boreholes without perforation. The initiation pressure also depends on both the ratio between the maximum horizontal principal stress and the vertical stress and the ratio between the maximum and minimum horizontal principal stresses. Additionally, perforation can effectively stress the coal seam, which extends the crack closure time. Field experiment results show that after hydraulic fracturing with the novel method, the gas drainage volume increased by a factor of 11.26 , and the drainage concentration increased by a factor of 2.12 compared with the ordinary gas drainage method.

Keywords: CBM extraction; hydraulic fracturing; perforation; high pressure water jet; crack conductivity; crack closure

\section{Introduction}

As a clean energy source, coal-bed methane (CBM) is obtained in two ways: ground extraction

\footnotetext{
${ }^{*}$ Corresponding author. Binwei Xia

Tel.: +86 13508382008, E-mail address: liuyoon@cqu.edu.cn, Address: Chongqing university, China.
} 
and underground extraction. In China, the volume of CBM obtained by underground extraction is 15 billion $\mathrm{m}^{3}$, accounting for $1 / 2$ of the total extraction volume. With increasing mining depth, the permeability of coal seams worsens progressively, and underground CBM extraction becomes more and more difficult. Therefore, intensified pressure-relief gas extraction techniques are widely used, such as deep-hole pre-split blasting (Liu et al., 2011), water-jet cutting (Lu et al., 2010), hydraulic flushing (Li et al., 2011) and hydraulic fracturing (Wang et al., 2014; Cai et al., 2014). Hydraulic fracturing has been widely used because of its broad stress relief and simplicity. Such problems as crack propagation toward the roof or floor, disorderly propagation, and fast closure often occur during hydraulic fracturing, leading to poor fracture conductivity and low CBM extraction efficiency.

The theory of hydraulic crack propagation and closure in coal seams is used in hydraulic fracturing in oil and gas reservoirs. It is generally believed that the horizontal stress difference is the major factor influencing crack propagation (Chitrala et al., 2013; Paine and Please, 1994). In addition, crack propagation is related to the differences in the crustal stress, elastic modulus, and fracture toughness; the interfacial strength between the coal seam and the roof and floor; and the pressure distribution and rheological behavior of the fracturing fluid (Abass et al., 1996; Guo et al., 1993; Guo et al., 1993). To allow fractures to propagate in the reservoirs, the crack initiation direction can be controlled by perforating wellbores (Zhang et al., 2004). Due to the impact of stress, fracture reorientation will occur over a short distance. No research on crack propagation during hydraulic fracturing in underground coal mines has been conducted.

Crack closure is generally believed to depend on the effective stress (Matsuki et al., 2008). Sensitivity can explain the practical problems encountered in oil and gas production (Giwelli et al., 2009). For example, the main cause of reduced connectivity in naturally fractured reservoirs is an increased effective stress. When the effective stress increases, the fracture will close; when the effective stress is reduced, the fracture width will increase. A common approach to maintaining the effective stress of reservoir fractures is proppant filling. However, in the case of coal bed fracturing, proppants are easily embedded in coal due to the low coal bed hardness, so the proppants cannot support the fracture. In addition, underground working sites often do not have adequate proppant filling conditions. Therefore, it is imperative to find a novel method to effectively mitigate crack closure in coal bed hydraulic fracturing. This paper presents a method for orientating crack propagation and lengthening crack closure that is suitable for hydraulic fracturing in underground 
coal mines. A high-pressure water jet is used parallel to the coal bed inclination in a borehole, and then hydraulic fracturing is performed. The stress field distribution perforations, crack initiation pressure, and crack propagation direction are analyzed, and the effect of perforation on the fracture conductivity is studied based on Hertz contact theory and the planar seepage model. Furthermore, a field test is conducted using this method, thereby providing a theoretical and technical foundation for efficient gas extraction.

\section{Stress Distribution of Coal around a Perforation}

Perforation in a wellbore can change the crack propagation direction over a certain distance. Based on this idea, a method was proposed for underground hydraulic fracturing that orients the crack propagation by a perforation developed by a high-pressure water jet, as shown in Figure 1. Several oriented boreholes were arranged on both sides of hydraulic fracturing boreholes. Then, perforation was performed parallel to the coal bed inclination within both the fracturing boreholes and the oriented boreholes using high-pressure water jets. Before the fracture was reoriented, the perforation holes within the oriented boreholes continued to influence the direction of the crack propagation.

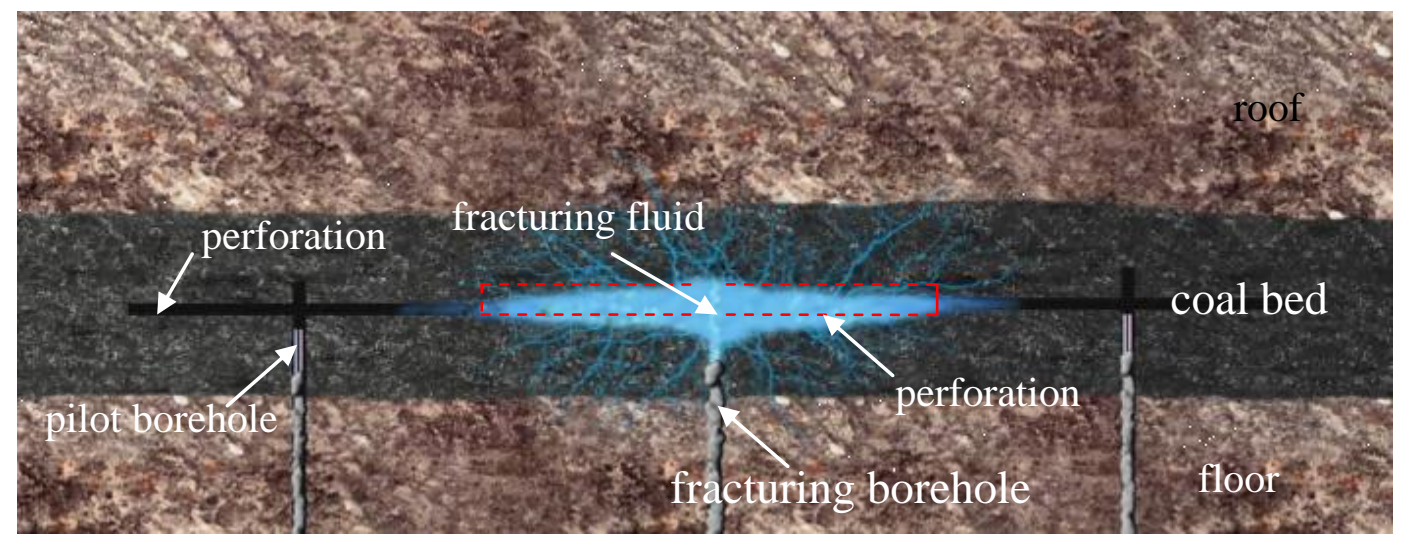

Figure 1: Method for orienting a hydraulic fracture within a coal bed

However, the mechanism of how the perforation within the fracturing borehole and the pilot borehole influences the initiation, propagation and closure of the crack remains unclear. Studies have shown that the crack initiation and propagation are related to the principal stress of coal and that the crack closure is linked to the effective stress. Therefore, the analysis of the stress distribution of coal around perforations is the basis of this study. Because the vertical stress is generally greater than the horizontal stress in China's mining areas, and the crack is vertical, the crack initiation and propagation in the horizontal direction are the most critical. The perforation is a 
quasi-conical shape in the coal seam; a model analyzing its physical stress is shown in Figure 2.

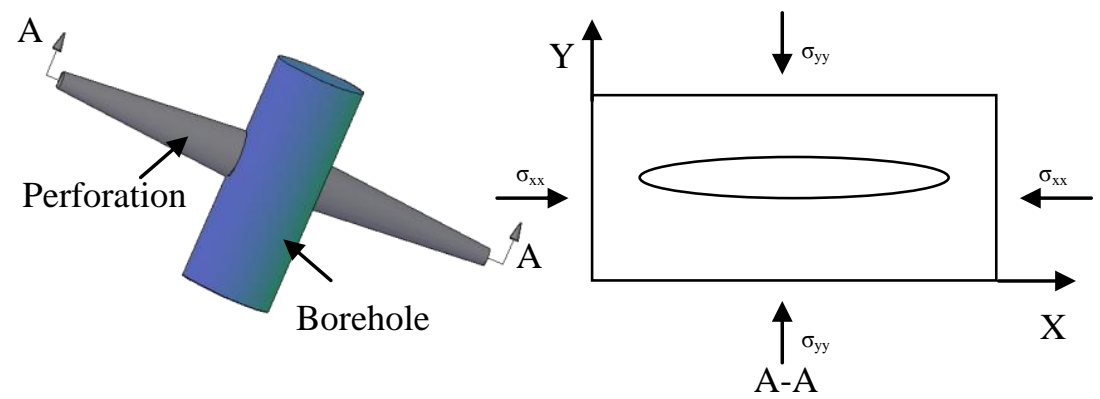

Figure 2: Physical stress analysis model of water jet perforation holes

A stress analysis was performed on the coal around the perforation using FLAC $^{3 \mathrm{D}}$ with a model area of $20 \mathrm{~m} \times 20 \mathrm{~m}$. The profile of the perforation was elliptical, and the semi-major axis and semi-minor axis of the ellipsoid were $2 \mathrm{~m}$ and $0.2 \mathrm{~m}$, respectively. The bidirectional stresses on model plane were both assumed to be $10 \mathrm{MPa}$, and the model parameters are shown in Table 1 .

Table 1 Parameters of the perforation stress analysis model

\begin{tabular}{|c|c|c|c|c|c|}
\hline Parameter & $\begin{array}{l}\text { Elastic } \\
\text { modulus } \\
(\mathrm{GPa})\end{array}$ & $\begin{array}{l}\text { Shear } \\
\text { modulus } \\
(\mathrm{GPa})\end{array}$ & $\begin{array}{c}\text { Cohesion } \\
\text { (MPa) }\end{array}$ & $\begin{array}{c}\text { Tensile } \\
\text { strength (MPa) }\end{array}$ & $\begin{array}{c}\text { Internal } \\
\text { friction angle } \\
\left(^{\circ}\right)\end{array}$ \\
\hline Value & 2.08 & 0.97 & 1.02 & 0.5 & 17 \\
\hline
\end{tabular}

Calculations were performed using the default precision, and the unbalanced force was monitored during the calculation process. As Figure 3 shows, a shear failure zone formed at the tip of the perforation. According to the maximum tensile stress criterion, a crack will be initiated when the pressure of the fracturing fluid exceeds the tensile strength of coal. Under the action of hydraulic pressure, a crack initiates at the tip of the perforation during hydraulic fracturing. For non-perforated cylindrical boreholes, an annular failure zone, a plastic zone, an elastic zone and an initial stress zone were formed from the interior to the exterior after drilling. The stresses around the boreholes were equal. The crack initiation location of the borehole was random under hydraulic pressure, which led to disorderly crack propagation. 


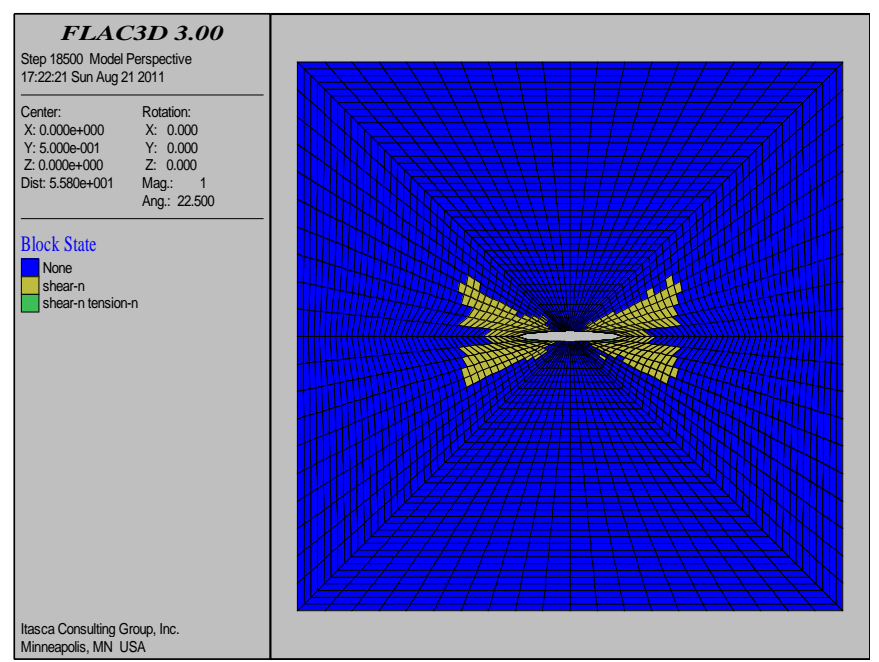

Figure 3: Distribution of the shear failure zone in perforated coal

The minimum principal stress direction determined the direction of the fracture. The included angle between the minimum principal stress and the horizontal plane was calculated by the following formula:

$$
\tan 2 \theta=\frac{2 \tau_{x y}}{\sigma_{x x}-\sigma_{y y}}
$$

where $\theta$ included angle between the maximum principal stress and the horizontal plane $\tau_{x y} \_$plane shear stress

On the X-axis, the values of $\sigma_{x x}$ and $\sigma_{y y}$ were determined at intervals of $0.5 \mathrm{~m}$ from the coordinates $(2,0)$ until the boundary coordinates $(10,0)$. The minimum principal stress direction was calculated under the boundary conditions of $\left(\sigma_{x x}, \sigma_{y y}\right)=(10,8),(10,9),(10,10),(10,11),(10,12)$ and $(10,13)$; the results of the calculation are shown in Figure 4.

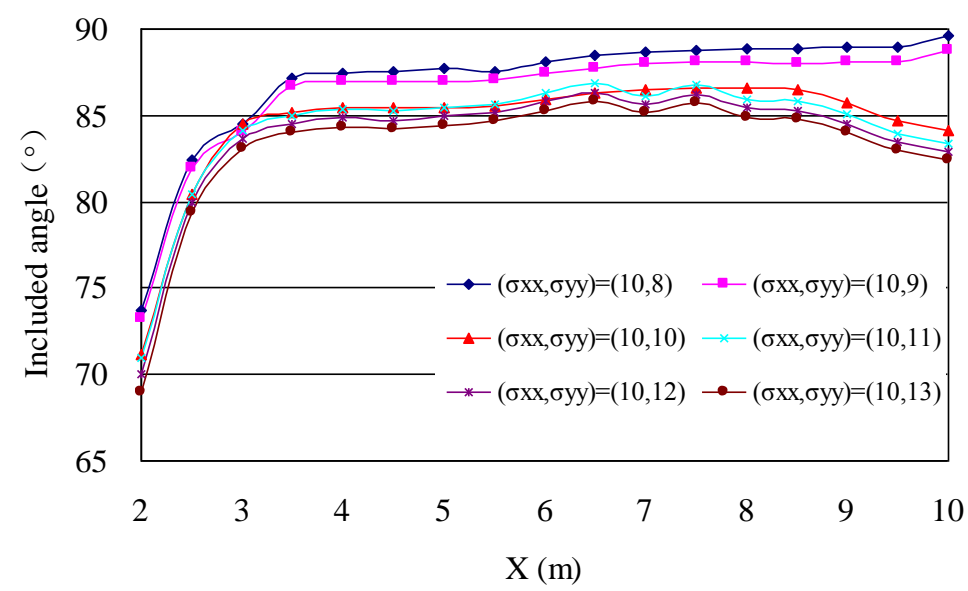

Figure 4: Minimum principal stress angles on the $\mathrm{X}$-axis under different boundary conditions

Because the stress was concentrated at the perforation tip, the included angle between the minimum principal stress and the $\mathrm{X}$-axis was small at the tip. However, at a distance of $0.5 \mathrm{~m}$ to 1 
$\mathrm{m}$ from the tip, the angle suddenly increased. Additionally, at locations far away from the tip, the direction of the minimum principal stress was approximately vertical to the X-axis. When $\left(\sigma_{x x}, \sigma_{y y}\right)$ $=(10,8),(10,9)$, the minimum principal stress angle increased gradually with increasing distance, but when $\left(\sigma_{x x}, \sigma_{y y}\right)=(10,10),(10,11),(10,12)$ and $(10,13)$, the minimum principal stress angle decreased more than $8.5 \mathrm{~m}$ away from the center. The direction of the maximum principal stress on the $\mathrm{X}$-axis provided a basis for a theoretical calculation to estimate the crack propagation and borehole layout distance.

When a fracture occurs, whether the fracture is horizontal or vertical depends on the direction of the minimum principal stress, and the fracture will always be vertical to the minimum principal stress. The most ideal fracture occurrence in a coal seam is when the fracture is parallel to the coal seam direction, which means the fracture will only expand in the coal seam rather than the roof or floor of the coal seam. Whether the perforation can alter the fracture depends on the direction of the minimum principal stress after perforation. A calculation of the minimum principal stress shows that the minimum principal stress is approximately vertical to the perforation and therefore the coal seam tendency. This result indicates that a perforation can generate a nearly ideal fracture in a coal seam. Because the minimum principal stress and maximum principal stress are mutually perpendicular to each other, and as the direction of fracture expansion is determined by the maximum principal stress, the fractures will expand toward the perforation direction after the crack initiation.

\section{Crack Initiation Pressure}

\subsection{Theoretical analysis of the crack initiation pressure}

An excessively large crack initiation pressure can lead to the crack extending towards the coal seam roof or floor, which is the primary cause of disorderly crack propagation as well as severe roof and floor failure. Based on the analysis of the stress distribution of the borehole and the perforation, the crack initiation pressure of perforated coal was calculated. The stress analysis around a perforation perpendicular to the borehole is shown in Figure 5, where the angle between the borehole and the vertical stress is denoted by $\psi$, and the included angle between the borehole axis and the minimum horizontal principal stress is denoted by $\beta$. 


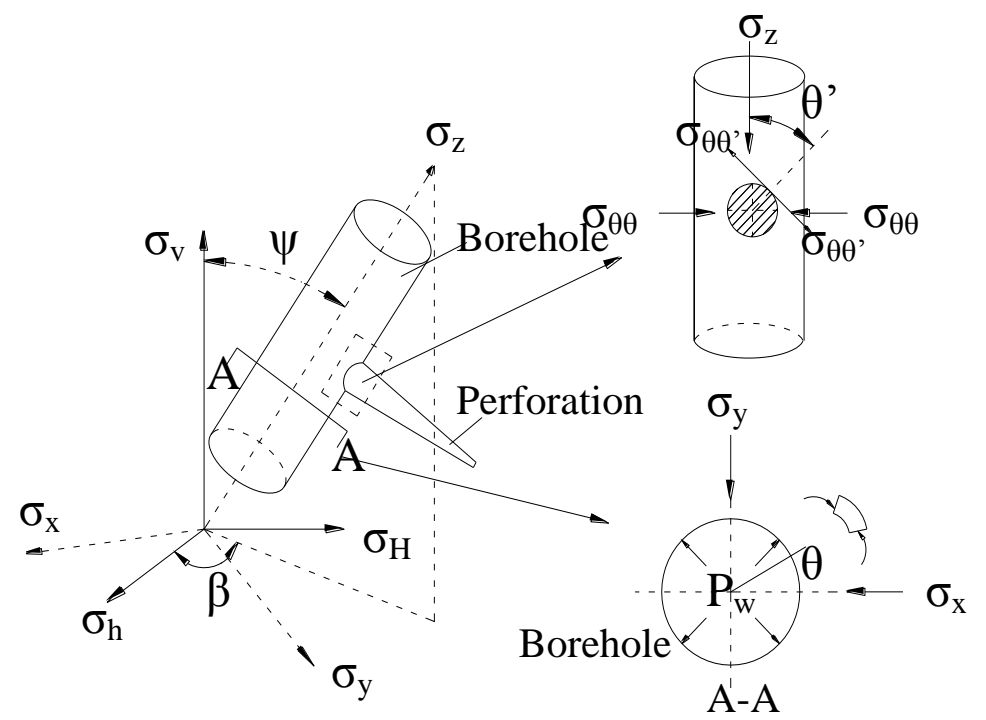

Figure 5: Stress analysis of the borehole and perforation

Based on the findings of Aadnoy (Aadnoy and Chenevert, 1987), the stress distribution of the coal around the perforation was obtained as follows:

$$
\begin{gathered}
\sigma_{r}=P_{w} \\
\begin{array}{c}
\sigma_{\theta \theta^{\prime}}=\left(\sigma_{x}+\sigma_{y}+\sigma_{z \theta}\right)-2\left(\sigma_{x}+\sigma_{y}-\sigma_{z \theta}\right) \cos 2 \theta^{\prime}-2\left(\sigma_{x}-\sigma_{y}\right) \\
\left(\cos 2 \theta+2 \cos 2 \theta \cos 2 \theta^{\prime}\right)-4 \tau_{x y}(1+2 \cos 2 \theta) \sin 2 \theta-4 \tau_{z \theta} \sin 2 \theta^{\prime}-P_{w}\left(2 \cos 2 \theta^{\prime}+2\right)^{2}
\end{array} \\
\sigma_{z \theta}=\sigma_{z}-2 v\left(\sigma_{x}-\sigma_{y}\right) \cos 2 \theta-4 v \tau_{x y} \sin 2 \theta \\
\tau_{r \theta}=\tau_{r z}=0 \\
\tau_{\theta z}=2\left(-\tau_{x z} \sin \theta+\tau_{y z} \cos \theta\right)
\end{gathered}
$$

where $\sigma_{r}$ is the radial stress, $\mathrm{MPa} ; \sigma_{x}, \sigma_{y}$ and $\sigma_{z}$ are the normal stresses, respectively, $\mathrm{MPa}$, with $\sigma_{z}$ parallel to the borehole axis; $\sigma_{\theta \theta}$ and $\sigma_{z \theta}$ are the tangential and axial stresses, respectively, at a perforation orientation angle of $\theta, \mathrm{MPa} ; \sigma_{\theta \theta^{\prime}}$ is the tangential stress at a perforation inclination angle of $\theta^{\prime}, \mathrm{MPa} ; \tau_{x y}, \tau_{x z}$ and $\tau_{y z}$ are the shear stresses in the rectangular coordinate system, MPa; $\tau_{r \theta}, \tau_{r z}$ and $\tau_{\theta z}$ are the tangential stresses in the cylindrical 
coordinate system, MPa; $P_{w}$ is the hydrostatic pressure of the borehole, MPa; and $v$ is Poisson's ratio for coal and rock.

Among these, $\sigma_{x}, \sigma_{y}, \sigma_{z}, \tau_{x y}, \tau_{x z}$ and $\tau_{y z}$ can be expressed using the ground stresses $\sigma_{H}, \sigma_{h}$ and $\sigma_{v}$ as

$$
\begin{gathered}
\sigma_{x}=\left(\sigma_{h} \cos ^{2} \beta+\sigma_{H} \sin ^{2} \beta\right) \cos ^{2} \psi \\
\sigma_{y}=\sigma_{h} \sin ^{2} \beta+\sigma_{H} \cos ^{2} \beta \\
\sigma_{z}=\left(\sigma_{h} \cos ^{2} \beta+\sigma_{H} \sin ^{2} \beta\right) \sin ^{2} \psi-\sigma_{v} \cos ^{2} \psi \\
\tau_{y z}=0.5\left(\sigma_{H}-\sigma_{h}\right) \sin 2 \beta \sin \psi \\
\tau_{z x}=0.5\left(\sigma_{h} \cos ^{2} \beta+\sigma_{H} \sin ^{2} \beta-\sigma_{v}\right) \sin 2 \psi \\
\tau_{x y}=0.5\left(\sigma_{H}-\sigma_{h}\right) \sin 2 \beta \cos \psi
\end{gathered}
$$

where $\sigma_{H}, \sigma_{h}$ and $\sigma_{v}$ are the maximum horizontal ground stress, the minimum horizontal ground stress and the vertical ground stress, respectively, $\mathrm{MPa} ; \beta$ is the declination angle of the borehole relative to $\sigma_{h},{ }^{\circ}$; and $\psi$ is the declination angle of the borehole relative to $\sigma_{v},{ }^{\circ}$.

The maximum principal stress criterion considered that for materials in complex stress states, yield failure occurs when a principal stress exceeded its tensile strength (Hossain et al., 2000). The principal stress of the coal surrounding the perforation holes can be expressed as

$$
\begin{gathered}
\sigma_{1}=\sigma_{r} \\
\sigma_{2}=\frac{1}{2}\left[\left(\sigma_{\theta \theta^{\prime}}+\sigma_{z \theta}\right)+\sqrt{\left(\sigma_{\theta \theta^{\prime}}-\sigma_{z \theta}\right)^{2}+4 \tau_{\theta z}^{2}}\right] \\
\sigma_{3}=\frac{1}{2}\left[\left(\sigma_{\theta \theta^{\prime}}+\sigma_{z \theta}\right)-\sqrt{\left(\sigma_{\theta \theta^{\prime}}-\sigma_{z \theta}\right)^{2}+4 \tau_{\theta z}^{2}}\right]
\end{gathered}
$$

$\sigma_{3}$ formed the maximum tensile stress around the perforation. If the effect of the gas pressure $\left(P_{g}\right)$ inside the coal were taken into account, the crack initiation pressure $\left(\sigma_{f}\right)$ of coal could be expressed as:

$$
\sigma_{f}=\sigma_{3}-P_{g}
$$


From formulas (3) and (16), $\sigma_{3}$ is related to the water injection pressure $P_{w}$. When $P_{w}$ increased continuously from $0, P_{w}$ would eventually equal $\sigma_{f}$. According to the crack initiation criterion, the following relationship was obtained:

$$
\sigma_{f} \leq-\sigma_{t}
$$

The tensile strength $\sigma_{t}$ of coal and rock is small (Aadnoy and Chenevert, 1987), so it can be regarded as 0 . Meanwhile, without considering the effect of the gas pressure on crack initiation, the following expression was derived from the above formulas:

$$
P_{w} \geq \frac{1}{2\left(\cos 2 \theta^{\prime}+1\right)}\left[\begin{array}{l}
\left(\sigma_{x}+\sigma_{y}+\sigma_{z \theta}\right)-2\left(\sigma_{x}+\sigma_{y}-\sigma_{z \theta}\right) \cos 2 \theta^{\prime}-2\left(\sigma_{x}-\sigma_{y}\right) \\
\left(\cos 2 \theta+2 \cos 2 \theta \cos 2 \theta^{\prime}\right)-4 \tau_{x y}(1+2 \cos 2 \theta) \sin 2 \theta-4 \tau_{z \theta} \sin 2 \theta^{\prime}-\frac{\tau_{\theta_{z}}^{2}}{\sigma_{z \theta}}
\end{array}\right]
$$

Formula (18) can be applied to calculate the crack initiation pressure at boreholes and perforations of any angle. For computational simplicity, only parallel boreholes with axial directions along the minimum horizontal principal stress direction were considered, i.e., $\psi=90^{\circ}, \quad \beta=0^{\circ}$. The analysis in Section 2 showed that the crack initiation direction was parallel to the axial direction of perforation, i.e., $\theta=90^{\circ}$ (along the $\sigma_{H}$ direction), and under these conditions, $\theta^{\prime}=90^{\circ}$. The crack initiation pressure $P_{w f}$ at the perforation is

$$
P_{w f}=\frac{1}{4}\left[9 \sigma_{v}-\sigma_{h}-3 \sigma_{H}+2 v\left(\sigma_{v}-\sigma_{H}\right)\right]
$$

If there was no perforation, the role of gas pressure was ignored, the tensile strength of coal was regarded as 0 , and the borehole axis was parallel to $\sigma_{x}$. By analyzing the tangential stress around the borehole, the location of the crack initiation could be estimated to be $\theta=0^{\circ}$ (along the $\sigma_{v}$ direction) or $\theta=90^{\circ}$ (along the $\sigma_{H}$ direction) using the same method described above, so the crack initiation pressure of the horizontal boreholes $P_{w f}^{\prime}$ is

$$
\begin{gathered}
P_{w f}^{\prime}=\min \left(P_{w 0}^{\prime}, P_{w 90}^{\prime}\right) \\
P_{w 0}^{\prime}=3 \sigma_{H}-\sigma_{v} \\
P_{w 90}^{\prime}=3 \sigma_{v}-\sigma_{H}
\end{gathered}
$$

To compare the crack initiation pressure before and after perforation and to facilitate its 
calculation, the dimensionless parameter $\frac{P_{w f}}{\sigma_{v}}$ was introduced. Formulas (19)-(22) show that $\frac{P_{w f}}{\sigma_{v}}$ was only a function of $\frac{\sigma_{H}}{\sigma_{h}}$ and $\frac{\sigma_{H}}{\sigma_{v}}$; that is,

$$
\frac{P_{w f}}{\sigma_{v}}=f\left(\frac{\sigma_{H}}{\sigma_{h}}, \frac{\sigma_{H}}{\sigma_{v}}\right)
$$

According to the characteristics of the coal in China, different combinations of stresses $\sigma_{H} / \sigma_{h}$ and $\sigma_{H} / \sigma_{v}$ were selected, and Poisson's ratio for coal was set to 0.3 to calculate the crack initiation pressures with and without perforation (see Figure 6, where "P" represents the stress of the borehole with perforation, and "NP" represents the stresses of the borehole without perforation). Under the same stress conditions, the crack initiation pressure of the borehole with perforation was lower than that of the borehole without perforation. At the same horizontal stress ratio, a greater value of $\sigma_{H} / \sigma_{v}$ produced a larger difference in the crack initiation pressure. However, when the value of $\sigma_{H} / \sigma_{v}$ was constant, a greater value of $\sigma_{H} / \sigma_{h}$ produced a smaller difference in the crack initiation pressure.

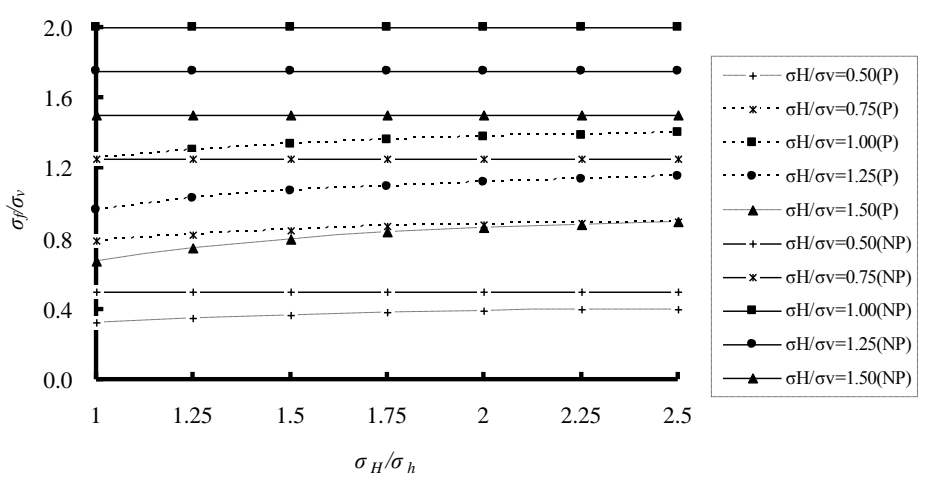

Figure 6: Comparison of the crack initiation pressure under different stress conditions

\subsection{Numerical analysis of the crack initiation pressure}

To verify the results of the theoretical analysis, the crack initiation pressures with and without perforation were compared using the numerical material failure process analysis software RFPA $^{2 \mathrm{D}}$-Flow. Models of boreholes with and without perforation were created with $30 \mathrm{~m} \times 30 \mathrm{~m}$ square regions (Figure 7). The horizontal stress $\sigma_{h}$ was applied to the upper portions of the models, and the horizontal stress $\sigma_{H}$ was applied to both sides; meanwhile, the bottoms of the models were set as simply supported constraints and impermeable boundaries. The injection 
pressure acted on the inner edges of the fractures, and it increased in $0.05 \mathrm{MPa}$ increments. The parameters in the model, such as the elastic modulus, strength, permeability coefficient and Poisson's ratio, were randomly assigned according to the Weibull distribution. Table 2 lists the parameters used for the calculations in the coal and rock mechanical models.
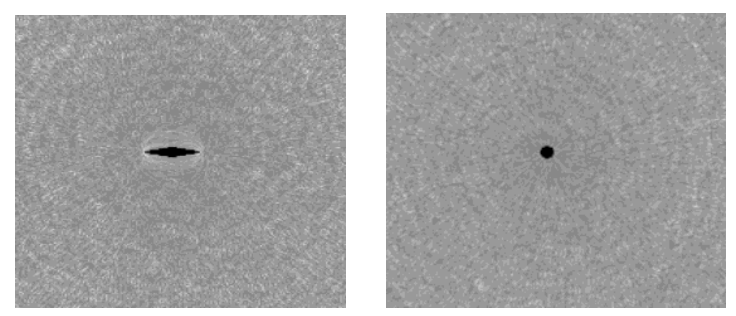

Figure 7 Numerical calculation model of the crack initiation pressure

Table 2 Mechanical parameters of coal and rocks

\begin{tabular}{|c|c|c|c|}
\hline Mechanical parameters & Parameter value & $\begin{array}{l}\text { Mechanical } \\
\text { parameters }\end{array}$ & Parameter value \\
\hline Mean degree & 3 & $\begin{array}{l}\text { Residual strength } \\
\text { coefficient }\end{array}$ & 0.1 \\
\hline Elastic modulus/GPa & 13 & $\begin{array}{c}\text { Pore water pressure } \\
\text { coefficient }\end{array}$ & 0.8 \\
\hline Internal friction angle $/^{\circ}$ & 33 & $\begin{array}{c}\text { Permeability } \\
\text { coefficient } / \mathrm{m} \cdot \mathrm{d}^{-1}\end{array}$ & 1.0 \\
\hline $\begin{array}{l}\text { Compressive } \\
\text { strength/MPa }\end{array}$ & 20 & Poisson's ratio & 0.3 \\
\hline $\begin{array}{c}\text { Tension-compression } \\
\text { ratio }\end{array}$ & 17 & Porosity & 0.15 \\
\hline
\end{tabular}

Crack initiation pressure values were calculated for both models under stress combinations of $\left(\sigma_{\mathrm{H}}, \sigma_{h}\right)=(10,8),(10,9),(10,10),(10,11)$ and $(10,12)$; the results are shown in Figure 8 . The numerical results showed that perforations could reduce the crack initiation pressure, and the rate of reduction increased with increasing $\sigma_{H} / \sigma_{v}$. The calculation results were identical to the theoretical analysis results. 


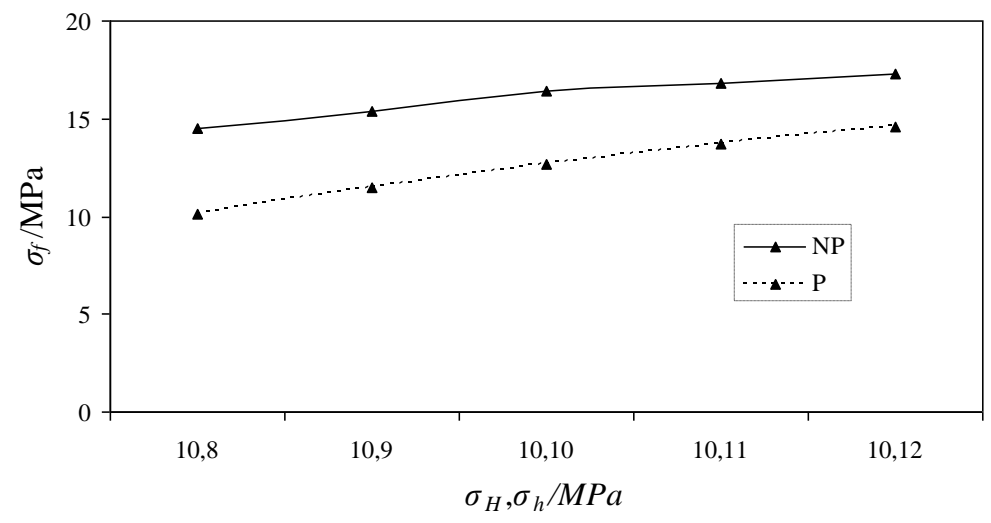

Figure 8: Comparison of crack initiation pressure values

\section{Law of Crack Propagation}

After the crack initiation at the tip of the perforation, if the direction of the maximum principal stress was parallel to the perforation axial direction, the crack would propagate in an orderly manner in the coal seam. If the angle of the maximum principal stress varied with respect to the perforation axial direction, the propagation direction of the crack would be unclear. The analysis in Section 2 showed that the included angle between the maximum principal stress and the perforation axial direction became larger with an increasing horizontal stress difference. Furthermore, when the boundary stress difference was large, e.g., $\left(\sigma_{x x}, \sigma_{y y}\right)=(10,13)$, the angle of the maximum principal stress increased gradually after $\mathrm{X}=8 \mathrm{~m}$, which meant that the crack might have reoriented at that position. To clarify the propagation characteristics of the crack under a greater boundary stress difference, the crack propagation under boundary stress combinations of $\left(\sigma_{x x}, \sigma_{y y}\right)=(10,12)$ and $(10,15)$ was analyzed using RFPA $^{2 \mathrm{D}}$-Flow. The physical models and parameters were the same as those used in the calculation of the crack initiation pressure in Section 3.

The results of the analysis showed that the cracks all initiated at the perforation tip hole under the two stress combination conditions, which was consistent with the results of the above analysis. After the crack initiation, the crack propagated along the crack initiation direction to a certain distance and was then reoriented towards the direction of the maximum principal stress; a greater horizontal stress difference caused a faster reorientation (Figures 9 (a), (b)). The reasons are as follows: when the horizontal stress difference was relatively large, the included angle between the shear failure zone of perforation and the horizontal plane increased. According to the maximum principal stress criterion, under the same hydraulic pressure conditions, the crack tended to propagate towards the plastic zone. Therefore, if a continuous plastic zone was formed in a coal 
seam using perforations, the sustained propagation of fractures in the coal seam could be achieved. To verify the role of perforations in guiding the propagation, a borehole was arranged on the periphery of the hydraulic fracturing hole and perforated to analyze the propagation characteristics of the crack under the horizontal stress combination of $\left(\sigma_{x x}, \sigma_{y y}\right)=(10,15)$. The results are shown in Figure 9 (c). As Figure 9 (c) shows, the presence of a continuous plastic zone at the perforation tip could guide the crack propagation in the coal seam, forming a single, effective fracture in the coal seam, thus laying the foundation for intensified gas extraction.

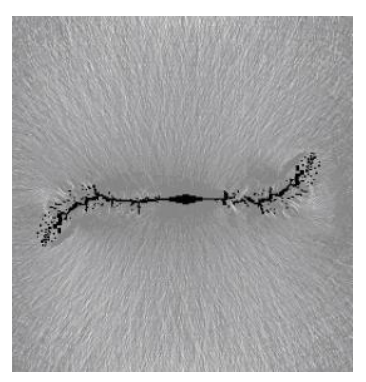

(a) $\left(\sigma_{x x}, \sigma_{y y}\right)=(10,12)$

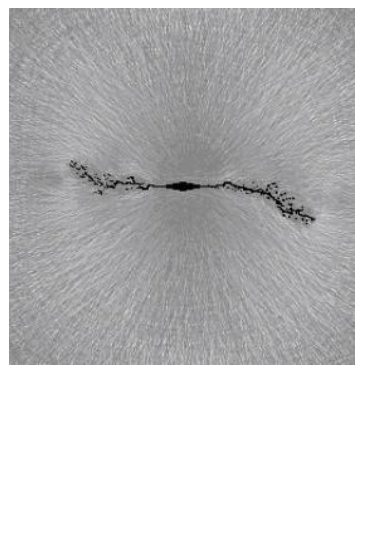

(b) $\left(\sigma_{x x}, \sigma_{y y}\right)=(10,15)$

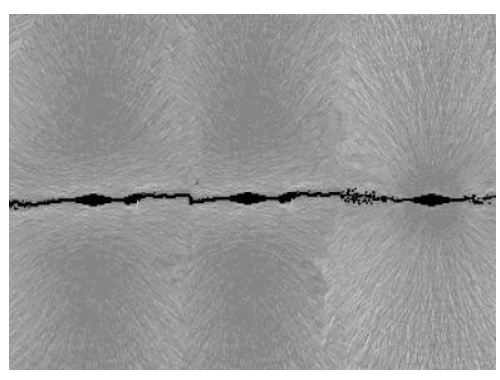

(c) $\left(\sigma_{x x}, \sigma_{y y}\right)=(10,15)$

Figure 9: Crack propagation law for a borehole with perforation

\section{Analysis of Crack Closure}

After hydraulic fracturing, a coal seam loses the support of high-pressure water. Meanwhile, with the coal seam being subjected to ground stresses and pore pressure, crack closure occurs. The deformation and closure of a crack leads to a sharp decline in conductivity. When the normal stress acting on the crack increased, supportive asperities are deformed and embedded in the contact surface, making the upper and lower contact surfaces close to each other, thus decreasing the crack opening. The original crack was wide, and the inter-crack supporting points were small in number and area. After being subjected to stress, the number of supporting points and the stressed area increased.

The two crack surfaces of the coal seam were regarded as rough surfaces, and asperities on the surfaces were deemed spherical. When the two contact surfaces were both isotropic, the contact process of the asperities along the rough surface length $\left(l_{\mathrm{s}}\right)$ resulted in plastic deformation. Then, the surface density $n_{0}$ of rough surface could be expressed as (Hong, 2004)

$$
n_{0}=\frac{N}{2 \bar{a}_{\mathrm{e}} l_{\mathrm{s}}}
$$


where $N$ is the number of asperities within a specified length range, and $\bar{a}_{\mathrm{e}}$ is the mean radius of the effective asperities.

The analysis revealed that the calculated height distribution of the asperities on the fracture contact surface profile was typically less than the actual height of the asperities. Therefore, Yamada (Yamada et al., 1987) determined a height distribution function $f(z)$ for asperities on rough surfaces by seeking the relationship between the asperity profile height distribution and the actual asperity distribution.

Before analyzing the asperity stress, the following assumptions were made: (1) the asperities on rough surfaces were spherical, with unchanging radius or curvature; (2) when the tops of the asperities were projected onto a plane parallel to the rough surface profile, the projection points were randomly distributed on the plane without overlapping each other; (3) the asperity contact complied with Hertz contact theory, and the impact of the frictional force acting on the asperities was ignored. The two rough surfaces were considered to have a closure volume $h$, and a coordinate system was established with the highest point of the two rough surfaces as the origin (Figure 10). The actual asperity distributions of the two rough surfaces were set as $f_{1}\left(z_{1}\right)$ and $f_{2}\left(z_{2}\right)$, respectively, and $\mathrm{d} z_{1}$ and $d z_{2}$ were taken on axes $O_{1} Z_{1}$ and $O_{2} Z_{2}$. Therefore, the numbers of asperities on the rough surfaces within the ranges of $z_{1}+\mathrm{d} z_{1}$ and $z_{2}+\mathrm{d} z_{2}$ could be expressed respectively as

$$
\begin{aligned}
& n_{01} A_{a} f_{1}\left(z_{1}\right) d z_{1} \\
& n_{02} A_{a} f_{2}\left(z_{2}\right) d z_{2}
\end{aligned}
$$

where $n_{01}$ is the surface density of asperities on surface $1 ; n_{02}$ is the surface density of asperities on surface 2; and $A_{a}$ is the nominal contact area.

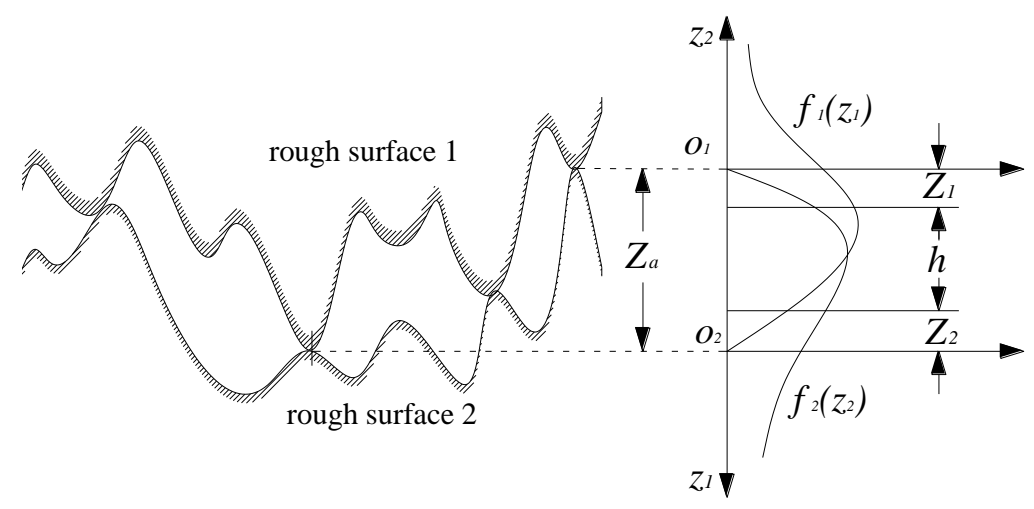

Figure 10: Schematic diagram of rough surface contact 


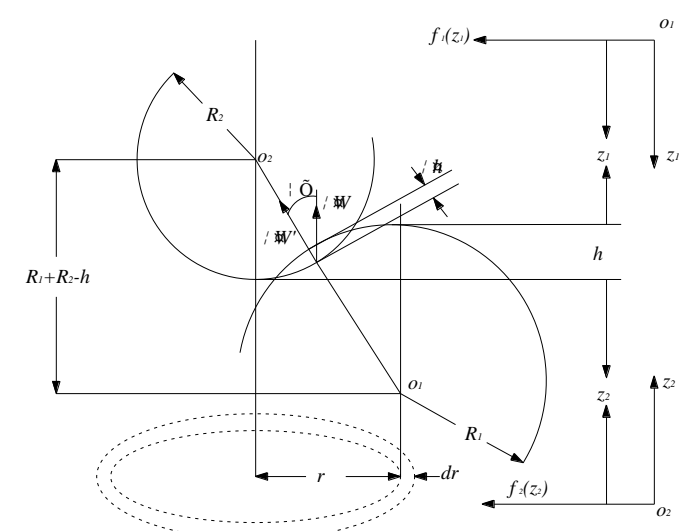

Figure 11: Schematic diagram for calculating the stress acting on asperities

When the two rough surfaces contacted each other, the closeable quantity was set as $Z_{a}$, and the closure displacement that occurred was set as $\Delta h$ (Figure 11). Under the action of pressure $\Delta W^{\prime}$, the normal component force $\Delta W$ was expressed as

$$
\Delta W=\Delta W^{\prime} \cos \varphi
$$

Because of the value of $\varphi$ was small, it was possible to approximate that $\Delta W \approx \Delta W^{\prime}$. Based on this assumption, the normal stress was expressed as (Atkin and Fox, 1980; Lurie and Belyaev, 2005)

$$
\Delta W=\frac{4}{3} E^{\prime}\left(\frac{R_{1} R_{2}}{R_{t}}\right)^{\frac{1}{2}} \Delta h^{\frac{3}{2}}
$$

In this formula $E^{\prime}=\frac{1+v_{1}^{2}}{E_{1}}+\frac{1+v_{2}^{2}}{E_{2}}$, where $v_{1}$ and $v_{2}$ are Poisson's ratios for contact surfaces 1 and 2, and $E_{1}$ and $E_{2}$ are the elasticity moduli of contact surfaces 1 and 2, respectively. For a coal crack, the mechanical properties of the two contact surfaces could be considered to be the same, i.e., $E^{\prime}=2 \frac{1+v}{E}$, where $v$ and $E$ are the Poisson's ratio and elastic modulus of coal, respectively. $R_{1}$ and $R_{2}$ are the radii of spherical asperities, $R_{\mathrm{t}}=R_{1}+R_{2}$; because $R_{\mathrm{t}}>>h$, and $R_{\mathrm{t}}>>\Delta h$, $\Delta h$ was expressed as

$$
\Delta h=h-\frac{r^{2}}{2 R_{\mathrm{t}}}
$$

The circular area was designated on a plane parallel to the contact surfaces with the spacing between two highest points of the asperities as the radius, denoted by $r$ (Figure 11). The contact point of the annular area between a circle with a radius of $r$ and a circle with a radius of $r+d r$ was 
analyzed. The occurrence of asperities within the annular area on surface 2 and the occurrence of the asperity peak point on surface 1 were considered mutually independent at a height of $z_{1}$, so the mutual embedded deformation $\Delta h$ of an asperity peak point on surface 1 at a height of $z_{1}$ and an asperity peak point on surface 2 at a height of $z_{2}$ was a complex event. Assuming that the adjacent asperities on the same surface were mutually independent, the contact point $\Delta n_{c}$ within the annular area was expressed as

$$
\begin{aligned}
\Delta n_{\mathrm{c}} & =A_{\mathrm{a}} n_{01} \frac{2 \pi r \mathrm{~d} r A_{\mathrm{a}} n_{02} f_{2}\left(z_{2}\right) \mathrm{d} z_{2}}{A_{a}} f_{1}\left(z_{1}\right) \mathrm{d} z_{1} \\
& =2 \pi n_{01} n_{02} A_{\mathrm{a}} f_{1}\left(z_{1}\right) \mathrm{d} z_{1} f_{2}\left(z_{2}\right) \mathrm{d} z_{2} r \mathrm{~d} r
\end{aligned}
$$

From formulas (29) and (30), the force when two asperities contact each other was denoted by $\Delta W \Delta n$. Therefore, the pressure of all of the asperities acting on surfaces 1 and 2 within a closable range of $Z_{\mathrm{a}}$ was expressed as

$$
\begin{aligned}
W & =\frac{8 \pi}{3} E^{\prime} A_{a} n_{01} n_{02}\left(\frac{R_{1} R_{2}}{R_{t}}\right)^{\frac{1}{2}} \int_{0}^{z_{a}} \int_{0}^{z_{a}-z_{1}} \int_{0}^{r_{0}} f_{1}\left(z_{1}\right) f_{2}\left(z_{2}\right)\left(h-\frac{r^{2}}{2 R_{t}}\right)^{\frac{3}{2}} r d r d z_{2} d z_{1} \\
& =\frac{2 \sqrt{2 \pi}}{15} E^{\prime} A_{a} n_{01} n_{02}\left(\frac{R_{1} R_{2}}{R_{t}}\right)^{\frac{1}{2}} \times \int_{0}^{z_{a}} \int_{0}^{z_{a}-z_{1}}\left\{\left[2 R_{t}\left(z_{a}-z_{1}-z_{2}\right)\right]^{\frac{5}{2}}-\left(z_{a}-z_{1}-z_{2}\right)^{5}\right\} f_{1}\left(z_{1}\right) f_{2}\left(z_{2}\right) d z_{2} d z_{1}
\end{aligned}
$$

In this formula, $r_{0}=\left(2 h R_{\mathrm{t}}-h^{2}\right)^{\frac{1}{2}}$, and $h=z_{\mathrm{a}}-z_{1}-z_{2}$. In the integral term of formula (31), the magnitude of the first term was far greater than the magnitude of the second term, so formula (31) was simplified as

$$
W=\frac{16 \pi}{15} E^{\prime} A_{\mathrm{a}} n_{01} n_{02}\left(R_{1} R_{2} R_{\mathrm{t}}\right)^{\frac{1}{2}} \int_{0}^{z_{\mathrm{a}}} \int_{0}^{z_{\mathrm{a}}-z_{1}}\left(z_{\mathrm{a}}-z_{1}-z_{2}\right)^{\frac{5}{2}} f_{1}\left(z_{1}\right) f_{2}\left(z_{2}\right) \mathrm{d} z_{2} \mathrm{~d} z_{1}
$$

$f_{1}\left(z_{1}\right)$ and $f_{2}\left(z_{2}\right)$ in formula (32) were expressed by the following formulas

$$
\begin{gathered}
\left\{\begin{array}{cc}
f_{1}\left(t_{1}\right)=\frac{1}{(2 \pi)^{\frac{1}{2}}} \exp \left[-\frac{\left(t_{1}-\bar{t}_{1}\right)^{2}}{2}\right] & t_{1} \geq 0 \\
0 & t_{1}<0
\end{array}\right. \\
\left\{\begin{array}{cc}
f_{2}\left(t_{2}, \lambda\right)=\frac{1}{(2 \pi)^{\frac{1}{2}}} \exp \left[-\frac{\left(t_{2}-\bar{t}_{2}\right)^{2}}{2}\right] & t_{2} \geq 0 \\
0 & t_{2}<0
\end{array}\right.
\end{gathered}
$$

where $t_{1}=\frac{z_{1}}{s_{1}}, t_{2}=\frac{z_{2}}{s_{2}}$ (and $s_{1}, s_{2}$ are the standard deviations of $f_{1}\left(z_{1}\right), f_{2}\left(z_{2}\right)$, respectively), 
and $\lambda=\frac{s_{2}}{s_{1}}$.

Formula (32) is the relational expression between the stress applied on the rough surface asperity $W$ and the closure volume $z_{\mathrm{a}}$. As formula (32) shows, these two variables exhibit a positive exponential relationship, which meant that the increase in the stress applied on the asperity could greatly increase the crack closure volume. At the macro level, an increase in the effective stress acting on the crack increases the crack closure volume. Reducing the effective stress applied on the coal is an effective method of reducing the coal crack closure.

The perforation in the borehole changed the stress field of the coal. The results from FLAC ${ }^{3 \mathrm{D}}$ showed that the stress around coal with perforations was smaller than the stress of coal without perforations, so the effective stress of the coal around the crack was reduced. The reduction of the effective stress could greatly slow down the closing of the coal crack.

\section{Analysis of the Crack Conductivity}

Only a major crack in a coal seam with rough surfaces is believed to be formed by hydraulic fracturing. At a constant gas pressure and temperature, the volume of gas in the coal remains unchanged. The gas flow in the fractures is characterized by laminar flow. Ignoring the influence of gravity, at a constant fluid medium volume, the fluid percolation in the fractures can be described by the Navier-Stokes equation.
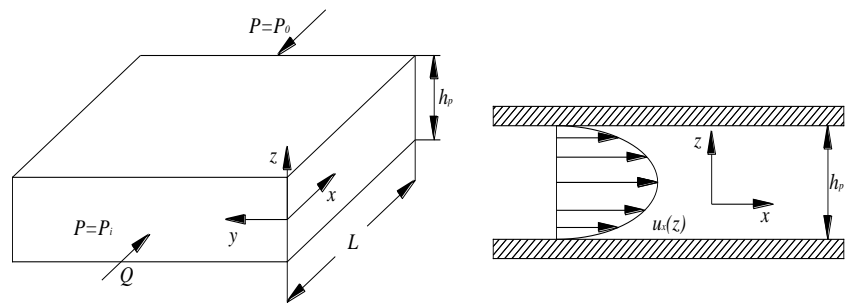

Figure 12 Schematic diagram of the planar seepage model

Based on the fluid flow characteristics of the planar model (Zimmerman and Gudmundur, 1996) (Figure 12), the velocity component remained unchanged in the $x$ and $y$ directions, and the change of velocity in the $z$ direction was parallel to the $z$-axis. The Navier-Stokes equation was rewritten as

$$
\mu \nabla^{2} u(z)=\nabla P
$$

where $\mathrm{P}$ is the fluid pressure $(\mathrm{Pa}), \mu$ is the fluid viscosity $(\mathrm{Pa} \cdot \mathrm{S})$, and $u$ is the fluid flow velocity $(\mathrm{m} / \mathrm{s})$. 
Because $u_{z}$ and $u_{y}$ were both 0 , the variation of $u_{x}$ depended on $z$. Incorporating the continuity equation, within the width $w$ region in the $y$-axis direction, the total volume flow passing through crack was obtained by integrating the velocity within the crack between $z=-h_{p} / 2$ and $z=+h_{p} / 2$ :

$$
\left.Q_{\mathrm{x}}=w \int_{-h_{p} / 2}^{+h_{p} / 2} u_{\mathrm{x}}(z) d z=w \int_{-h_{p} / 2}^{+h_{p} / 2} \frac{|\overline{\nabla P}|}{2 \mu} \mid z^{2}-\left(\frac{h_{p}}{2}\right)^{2}\right] d z=\frac{-|\overline{\nabla P}| w h_{p}^{3}}{12 \mu}
$$

where $h_{p}$ is height between two planes. The average velocity was expressed as

$$
\bar{u}_{\mathrm{x}}=\frac{Q_{\mathrm{x}}}{w h}=\frac{-|\overline{\nabla P}| h_{p}^{2}}{12 \mu}
$$

Formula (37) gives the relational expression between the crack height and the average gas seepage velocity. The velocity and height have a quadratic relationship, while the flow and height have a cubic relationship. Therefore, the reduction of the crack closure volume could increase the gas seepage velocity as well as the gas extraction yield.

\section{Field Experiment}

The test site was located in the S11203 roadway under the Fengchun mine, Chongqing, China. The Fengchun mine is considered to be prone to coal and gas bursting accidents. The No. 8 coal seam is the main coal seam, and its thickness is $0.9 \mathrm{~m}$ to $4.57 \mathrm{~m}$, with an average thickness of $2.2 \mathrm{~m}$. Its workable thickness is $0.9 \mathrm{~m}$ to $3.94 \mathrm{~m}$ with an average thickness of $1.8 \mathrm{~m}$. The gas content of the seam is $18.58 \mathrm{~m}^{3} / t$, the porosity is $4.79 \%$, and the permeability coefficient is $0.013 \mathrm{~m}^{2} /\left(M P a^{2} \cdot d\right)$. Its roof/floor is silty sandstone. Thus, the gas in the seam is difficult to drain.

The No. 8 coal seam, with an underground elevation of $+610.3 \mathrm{~m}$ to $+613.4 \mathrm{~m}$, and a burial depth of $449.9 \mathrm{~m}$, was the hydraulic fracturing coal seam considered in this study. The fracturing borehole was located in the $8 \#$ drill site, which was perpendicular to the seam, and finished in the No. 8 coal seam. The oriented boreholes were arranged in the north-south direction in the 8\# drill site under the S11203 roadway, a total of 4 oriented holes were designed, and their end points were at the same elevation as the hydraulic fracturing borehole, as shown in Figure 13.

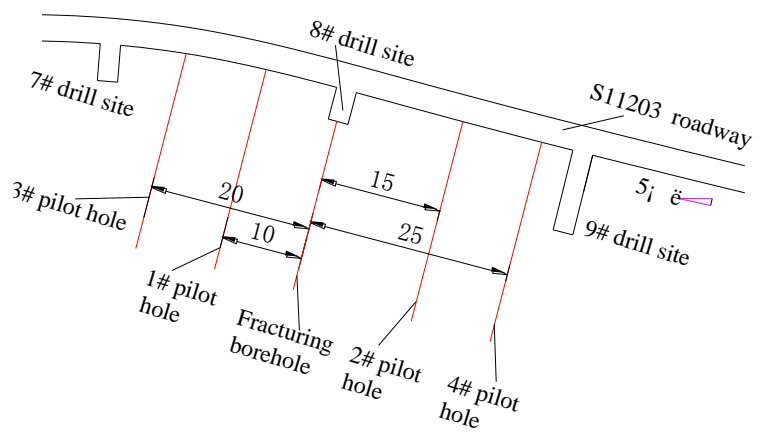


Figure 13: Layout of fracturing and pilot borehole

The hydraulic fracturing and orientation boreholes were perforated parallel to the coal seam with water jets. All of the hydraulic fracturing and orientation boreholes were sealed, and a stop valve was installed at the borehole top. The hydraulic fracturing borehole was connected to a high-pressure pump to perform hydraulic fracturing, and whether the crack was propagated to the oriented boreholes was determined by observing the water efflux status in the oriented boreholes. If water efflux was observed in the oriented boreholes, the stop valve would be closed. Hydraulic fracturing continued for a total of 6 hours and 20 minutes, when the injected water volume was 120 $\mathrm{m}^{3}$; a substantial amount of water flew out of the 4 oriented boreholes. The radius of fracturing in the coal seam was determined to exceed $25 \mathrm{~m}$. To verify the gas drainage effect after hydraulic fracturing, 6 drainage boreholes were arranged in the 8\# drill site under the $S 11203$ roadway, and 5 drainage boreholes were laid out in the $6 \#$ drill site, which had not adopted any intensified gas extraction measures. All of the drainage boreholes finished in the M8 coal seam, and the parameters were the same for all of the drill sites. The gas drainage effect between the two drill sites was compared.

The hydraulic fracturing drainage boreholes (6 holes in the $8 \#$ drill site) achieved a total gas drainage volume of $13,492.21 \mathrm{~m}^{3}$ (drained for 42 days), an average concentration of drained gas of $68 \%$, and an average drainage volume of a single borehole of $0.037 \mathrm{~m}^{3} / \mathrm{min}$. In comparison, ordinary holes (5 holes in the \#6 drill site) had a gas drainage volume of 3,053.55 $\mathrm{m}^{3}$ (drained for 42 days), an average concentration of drained gas of $32 \%$, and an average drainage volume of a single borehole of $0.0033 \mathrm{~m}^{3} / \mathrm{min}$, as shown in figure 14. After hydraulic fracturing, the gas drainage volume increased by a factor of 11.26, and the drainage concentration increased by a factor of 2.12 compared with the ordinary holes.

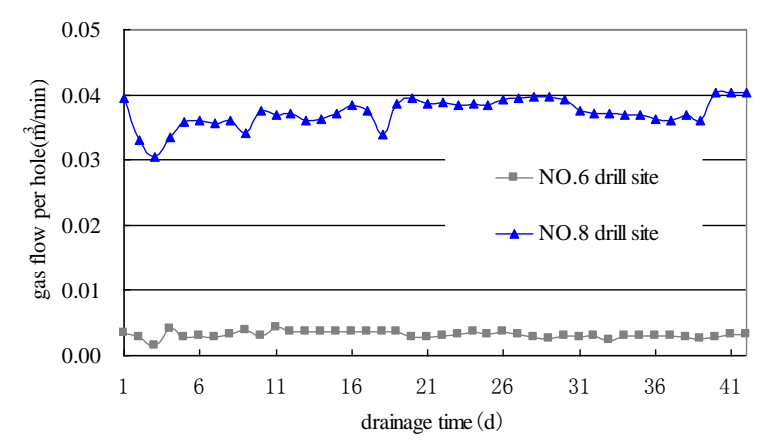

Figure 14 Comparison of the gas drainage volume

\section{Conclusions}


Targeting such issues as disorderly crack propagation in hydraulic fracturing underground coal mines, a method of crack orientation by perforation developed by water jets was proposed to facilitate orderly crack propagation in coal seams. The stress state of the perforation was analyzed, and the distribution characteristics of the shear failure at the perforation tip were found to cause the crack to initiate at the tip of the perforation. The maximum principal stress directions of coal with perforations under different stress boundary conditions were identified.

The stress state of the perforation was analyzed, and the stress distribution of the coal around the perforation was obtained. A crack initiation pressure calculation model that applies to perforated boreholes at any angle was developed. The crack initiation pressures of hydraulic fracturing with and without perforation were compared. The crack initiation pressure was lower for boreholes with perforations than borehole without perforations; for example, the pressure decreased more than 5 MPa when $\left(\sigma_{\mathrm{H}}, \sigma_{h}\right)=(10,8)$. At the same horizontal stress ratio, a greater $\sigma_{H} / \sigma_{v}$ ratio led to a larger difference in the crack initiation pressure. On the contrary, with a constant $\sigma_{H} / \sigma_{v}$ ratio, a greater $\sigma_{H} / \sigma_{h}$ ratio led to a smaller difference in the crack initiation pressure. The crack initiation pressures before and after perforation were compared using $\mathrm{RFPA}^{2 \mathrm{D}}$-Flow, and the results agreed with the theoretical calculations.

The crack initiation location and propagation characteristics under different horizontal stress conditions were numerically analyzed, and the results indicated that perforations could change the crack reorientation distance. A single, effective crack in a coal seam could be formed by adjusting the spacing between perforations. Additionally, a law for gas seepage in a crack was obtained based on the N-S equation. The comparative analysis concluded that the single, effective fracture formed by perforation can achieve the prolonged, efficient extraction of gas.

The field experiment results show that after hydraulic fracturing with the novel method, the gas drainage volume increased by a factor of 11.26 , and the drainage concentration increased by a factor of 2.12, compared with the ordinary gas drainage method.

\section{Acknowledgments}

This paper is jointly supported by the Program for Changjiang Scholars and Innovative Research Team in University (IRT1235), the National Science Foundation for Distinguished Young Scholars of China, (51104191), the Chongqing Science Foundation (CSTCJJA90004) and the Scientific Research Foundation of State Key Lab. of Coal Mine Disaster Dynamics and Control 
(2011DA105287-FW201204).

\section{References}

Aadnoy B. S., Chenevert M. E., 1987. Stability of Highly Inclined Boreholes. SPE Drilling Engineering. 2, 364-374.

Abass H. H., Hedayati S., Meadows D. L., 1996. Non-planar crack propagation from a horizontal wellbore: experimental study. SPE Production and Facilities. 11, 133-137.

Atkin R. J., Fox N., 1980. An Introduction to the Theory of Elasticity. Longman Group Ltd., London, 76-79.

Cai Y. D., Liu D. M., Mathews P. J., Pan Z.J., Elsworth D., Yao Y. B., Li J. Q., Guo X. Q., 2014. Permeability evolution in fractured coal-Combining triaxial confinement with X-ray computed tomography, acoustic emission and ultrasonic techniques. Int. J. Coal Geol. 122, 91-104.

Chitrala Y., Moreno C., Sondergeld Carl., Rai C., 2013. An experimental investigation into hydraulic crack propagation under different applied stresses in tight sands using acoustic emissions. J Petrol Sci Eng. 108, 151-161

Giwelli A.A., Sakaguchi K., Matsuki K., 2009. Experimental study of the effect of fracture size on closure behavior of a tensile fracture under normal stress. Int J Rock Mech Min. 46, 462-470.

Guo F., Morgenstern N.R., Scott J.D, 1993. An experimental investigation into hydraulic crack propagation-Part 1. Experimental facilities. Int J Rock Mech Min Sci Geomech Abstr. 30, 177-188. Guo F., Morgenstern N.R., Scott J.D, 1993. An experimental investigation into hydraulic crack propagation-Part 2. Single well tests. Int J Rock Mech Min Sci Geomech Abstr. 30, 189-202.

Hong C., 2004. Hydraulic fracturing in particulate materials. Georgia: Georgia Institute of Technology.

Hossain M.M., Rahman M.K., Rahman S.S., 2000. Hydraulic crack initiation and propagation: roles of wellbore trajectory, perforation and stress regimes. J Petrol Sci Eng. 27, 129-149.

Li B., Liu M. J., Liu Y. W., Wang N. H., Guo X. 1., 2011. Research on pressure relief scope of hydraulic flushing bore hole. Proc Eng, 26, 382-387.

Liu J. C., Wang H. T., Yuan Z. G., Fan X. G., 2011. Experimental Study of Pre-splitting Blasting Enhancing Pre- drainage Rate of Low Permeability Heading Face. Proc Eng. 26, 818-823.

Lu Y. Y., Liu Y., Li X. H., Kang Y., 2010. A new method of drilling long boreholes in low permeability coal by improving its permeability. Int. J. Coal Geol. 84, 94-102.

Lurie A. I., Belyaev A., 2005. Theory of Elasticity. Springer, Berlin, 174-175. 
Matsuki K., Wang E.Q., Giwelli A.A., Sakaguchi K. 2008. Estimation of closure of a fracture under normal stress based on aperture data. Int J Rock Mech Min, 45, 194-209.

Paine A. S., Please C. P., 1994. An improved model of crack propagation by gas during rock blasting-some analytical results. Int J Rock Mech Min Sci Geomech Abstr. 31, 699-706.

Wang T., Zhou W. B., Chen J. H., Xiao X., Zhao X. Y., 2014. Simulation of hydraulic fracturing using particle flow method and application in a coal mine. Int. J. Coal Geol. 121, 1-13

Yamada K., Tankeda N., Kagami J., 1978, Surface density of asperities and real distribution of asperity heights on rubbed surfaces. Wear. 47,15-20.

Zhang G. Q., Chen M., Wang X. S., 2004. Influence of perforation on formation fracturing pressure.

Pet Sci. 1, 56-61.

Zimmerman R. W., Gudmundur S. B., 1996. Hydraulic conductivity of rock fracture. Transp Porous Media. 23, 1-30.

\section{Appendix}

$\bar{a}_{\mathrm{e}} \quad$ mean radius of effective asperities

$A_{a} \quad$ nominal contact area

$E_{1} \quad$ elasticity modulus of contact surfaces 1

$E_{2} \quad$ elasticity modulus of contact surfaces 2

$f(z) \quad$ actual asperity distributions for asperities on rough surfaces

$h \quad$ closure volume

$h_{p} \quad$ height between two planes

$l_{\mathrm{s}} \quad$ rough surface length

$n_{0} \quad$ surface density

$N \quad$ number of asperities

P fluid pressure

$P_{w} \quad$ hydrostatic pressure of borehole

$P_{g} \quad$ gas pressure

$Q_{x} \quad$ total volume flow

$r \quad$ radius

$R_{1} \quad$ radii of spherical asperities 
$R_{2} \quad$ radii of spherical asperities

$S_{1} \quad$ the standard deviations of $f_{1}\left(z_{1}\right)$

$s_{2} \quad$ the standard deviations of $f_{2}\left(z_{2}\right)$

$u \quad$ fluid flow velocity

$\bar{u}_{\mathrm{x}} \quad$ average velocity

$v_{1} \quad$ Poisson's ratios of contact surfaces 1

$v_{2} \quad$ Poisson's ratios of contact surfaces 2

w width

$Z_{\mathrm{a}} \quad$ closable range

$\beta \quad$ declination angle of borehole relative to $\sigma_{h}$

$\Delta h \quad$ closure displacement

$\Delta n_{c} \quad$ contact point

$\Delta W^{\prime} \quad$ pressure on surface

$\Delta W \quad$ normal component force on surface

$\theta \quad$ included angle between the maximum principal stress and horizontal plane

$\mu \quad$ fluid viscosity

$v \quad$ Poisson's ratio for coal and rock.

$\sigma_{1} \quad$ major principal stress

$\sigma_{2} \quad$ secondary principal stress

$\sigma_{3} \quad$ third principal stress

$\sigma_{t} \quad$ tensile strength

$\sigma_{f} \quad$ crack initiation pressure

$\sigma_{H} \quad$ maximum horizontal ground stress

$\sigma_{h} \quad$ maximum horizontal ground stress

$\sigma_{r} \quad$ radial stress

$\sigma_{v} \quad$ vertical ground stress 
$\sigma_{x}, \sigma_{y}, \sigma_{z} \quad$ normal stresses

$\sigma_{\theta \theta}$ normal stresses tangential stresses at a perforation orientation angle of $\theta$

$\sigma_{z \theta} \quad$ normal stresses axial stresses at a perforation orientation angle of $\theta$

$\sigma_{\theta \theta^{\prime}} \quad$ normal stresses tangential stress at a perforation inclination angle of $\theta^{\prime}$

$\tau_{x y}, \tau_{x z}, \tau_{y z} \quad$ shear stresses in the rectangular coordinate system

$\tau_{r \theta}, \tau_{r z}, \tau_{\theta z} \quad$ tangential stresses in the cylindrical coordinate system

$\psi \quad$ declination angle of borehole relative to 